\title{
SISTEM INFORMASI POTENSI WISATA DI KABUPATEN KOLAKA TIMUR BERBASIS WEB
}

\author{
Muh. Alim Zulkifli* \\ Teknik Informatika, Universitas Nahdlatul Ulama Sulawesi Tenggara \\ email: kiflikeken.fd@gmail.com*
}

\begin{abstract}
Abstrak: Kabupaten Kolaka Timur merupakan salah satu Kabupaten di Provinsi Sulawesi Tenggara yang memiliki cukup banyak daerah potensi wisata. Namun masih banyak wisatawan yang tidak mengenal wisata yang terdapat di Kabupaten Kolaka Timur. Kurangnya pengetahuan tentang wisata tersebut disebabkan oleh informasi tentang tempat wisata yang masih minim dan belum dipublikasikan dengan baik. Dalam kasus tersebut, untuk membantu pihak terkait dan juga wisatawan dalam mengenal wisata yang terdapat di Kabupaten Kolaka Timur, maka dibangun sebuah website yang dapat memberikan informasi yang detail tentang wisata dan rute menuju tempat wisata yang terdapat di daerah Kabupaten Kolaka Timur. Untuk memberikan informasi rute, menggunakan Google Maps yang akan mengakses current location dari user menuju arah tempat wisata yang ingin dikunjungi. Dengan adanya website ini diharapkan dapat membantu wisatawan dalam mengenal potensi wisata yang ada di daerah Kabupaten Kolaka Timur dan juga membantu pengelola tempat wisata dalam mengenalkan daerah wisata yang ada di Kabupaten Kolaka Timur.
\end{abstract}

Kata Kunci : Kolaka Timur, Website, Wisata

Abstract: East Kolaka Regency is one of the regencies in Southeast Sulawesi Province which has quite a lot of tourism potential areas. However, there are still many tourists who do not know the tourism in East Kolaka Regency. The lack of knowledge about tourism is caused by information about tourist attractions that is still minimal and has not been published properly. In this case, to assist related parties and tourists in getting to know tourism in East Kolaka Regency, a website was built that can provide detailed information about tourism and routes to tourist attractions in the East Kolaka Regency area. To provide route information, use Google Maps which will access the current location of the user towards the direction of the tourist spot they want to visit. With this website, it is hoped that it can help tourists recognize the tourism potential in the East Kolaka Regency and also help the managers of tourist attractions in introducing tourist areas in East Kolaka Regency.

Keywords : East Kolaka, Website, Travel

\section{PENDAHULUAN}

Perkembangan Teknologi dewasa ini memiliki dampak yang sangat besar terhadap perubahan yang terjadi, misalnya seperti derasnya arus informasi yang semakin terbuka dan tentu itu memudahkan kita semua dalam mencari informasi yang kita butuhkan. Dengan hanya mengakses website atau search engine saja kita bisa dengan mudah menemukan informasi yang kita butuhkan termasuk informasi tentang wisata sekalipun. Sayangnya dalam derasnya arus informasi, seolah informasi potensi wisata yang ada di kolaka timur tidak banyak yang muncul, padahal dengan bentang alam yang menakjubkan, Kabupaten Kolaka Timur memiliki segudang potensi untuk pariwisata.

Kabupaten Kolaka Timur terletak pada Provinsi Sulawesi Tenggara bagian barat yang memiliki tempat wisata yang sangat menarik untuk dikunjungi. Letaknya yang strategis dan bentang alam yang unik memberikan pesona tersendiri bagi penikmatnya. Berdasarkan letaknya ini, Kabupaten Kolaka Timur memiliki tiga macam potesi wisata yaitu, potensi wisata alam, potensi wisata budaya dan potensi wisata buatan. Tetapi selama ini potensi pariwisata di Kabupaten Kolaka Timur kurang diperhatikan oleh wisatawan baik lokal maupun mancanegara. Hal ini dapat dilihat pada data Badan Pusat Statistik Sulawesi Tenggara [1], dimana data
Badan Pusat Statistik tidak mencantumkan data wisata yang ada di Kabupaten Kolaka Timur, seperti tercantum pada tabel 1 .

Tabel 1. Jumlah Kunjungan Wisatawan per Kabupaten/Kota Pada Tahun 2017 dan 2019

\begin{tabular}{|c|c|c|c|c|}
\hline No & $\begin{array}{c}\text { Kabupaten } \\
\text { /Kota }\end{array}$ & $\begin{array}{l}\text { Banyak } \\
\text { Wisata } \\
2017\end{array}$ & $\begin{array}{l}\text { Banyak } \\
\text { Wisata } \\
2018\end{array}$ & $\begin{array}{l}\text { Banyak } \\
\text { Wisata } \\
2019\end{array}$ \\
\hline 1 & Buton & 77 & 66 & 148 \\
\hline 2 & Muna & 125 & 104 & 149 \\
\hline 3 & Konawe & 30 & 30 & 44 \\
\hline 4 & Kolaka & 84 & 80 & 87 \\
\hline 5 & $\begin{array}{l}\text { Konawe } \\
\text { selatan }\end{array}$ & 12 & 12 & 24 \\
\hline 7 & Bombana & 107 & 109 & 113 \\
\hline 8 & Wakatobi & 82 & 82 & 166 \\
\hline 9 & $\begin{array}{l}\text { Kolaka } \\
\text { Utara }\end{array}$ & 37 & 38 & 45 \\
\hline 10 & $\begin{array}{l}\text { Buton } \\
\text { Utara }\end{array}$ & 26 & 26 & 28 \\
\hline 11 & $\begin{array}{l}\text { Konawe } \\
\text { Utara }\end{array}$ & 20 & 20 & 29 \\
\hline 12 & $\begin{array}{l}\text { Kolaka } \\
\text { Timur }\end{array}$ & 6 & 6 & 43 \\
\hline
\end{tabular}




\begin{tabular}{llc}
\hline & Konawe & 224 \\
13 & Kepulauan & \\
\hline
\end{tabular}

Untuk menarik minat wisatawan berkunjung di Kabupaten Kolaka Timur, dibutuhkan sebuah media informasi yang dapat di gunakan oleh wisatwan untuk mencari informasi detail tentang wisata yang ada di Kolaka Timur. Salah satu media yang paling mudah di akses secara realtime oleh banyak kalangan adalah website. Website sangat mudah untuk di akses sehingga banyak digunakan dalam banyak bidang yang ada, dengan era informasi seperti saat ini, website dapat menjadi alat bantu penyediaan informasi yang sangat efektif dan juga efisien. Kelebihan website selain mudah di akses adalah menarik indera dan menarik minat, karena dapat menggabungkan elemen interaktif antara pandangan, suara dan animasi, maka website merupakan sarana penyebaran informasi yang sangat efektif [2].

Berdasarkan uraian yang ada, dapat di simpulkan bahwa terdapat banyak potensi wisata di Kabupaten Kolaka Timur yang belum diketahui oleh wisatawan, dikarenakan minimnya informasi detail mengenai wisata yang terdapat di Kolaka Timur. Untuk itulah penulis berinisatif untuk membangun sebuah sistem informasi wisata berbais website di Kantor Dinas pariwisata agar dapat memberikan informasi tentang potensi wisata yang ada di Kolaka Timur yang detail dan menarik sehingga bisa di akses dengan mudah oleh siapa saja dan kapan saja. Dalam website tersebut juga akan berisi teks, gambar dan video tentang objek wisata yang ada di Kolaka Timur serta dapat memberikan petunjuk arah menuju lokasi wisata dengan bantuan Google Maps sehingga akan sangat membantu para wisatawan yang hendak berkunjung ke Kolaka Timur

\section{TINJAUAN PUSTAKA}

Berdasarkan studi literatur terdahulu sebagai pendukung penelitian ini, ditemukan penelitian dengan tema sejenis. Penelitian pertama dengan judul "Perancangan Sistem Informasi Pariwisata Berbasis Web Di Dinas Kebudayaan dan Pariwisata Kabupaten Muna". Hasil dari penelitian adalah Sistem informasi berbasis web dapat membantu kelancaran operasional pariwisata dinas kebudayaan dan pariwisata kabupaten muna serta dapat memperluas jangkauan penyampaian informasi pariwisata di bandingkan dengan sistem manual [3].

Penelitian kedua oleh [4] dengan judul "SistemInformasi Pariwisata Daerah Kabupaten Wonogiri berbasis Web". Hasil dari penelitian tersebut adalah Pembangunan sistem informasi pariwisata kabupaten wonogiri merupakan alat bantu dalam penyampaian promosi informasi Kawasan wisata dan budaya yang ada di kabupaten wonogiri agar lebih menarik wisatawan.

Penelitian ketiga oleh [5] dengan judul "Pengembangan Sistem Informasi Pariwisata
Surakarta dengan Menggunakan Macromedia Flash”. Hasil dari penelitian tersebut adalah Sistem Informasi pariwisata berbasis macromedia flash ini di manfaatkan oleh pihak dinas pariwisata seni dan budaya Surakarta untuk meningkatkan kualitas pelayana kepada masyarakat dalam memberikan informasi tebtang pariwisata Surakarta yang lebih menarik dan informatif

Berdasarkan uraian penelitian terdahulu mengenai sistem informasi wisata, semuanya ditujukan untuk memudahkan pihak Dinas Pariwisata (subjek) sedangkan untuk Wisatawan (obyek) hanya menerima informasi yang monoton, sedangkan yang penulis akan kembangkan adalah sistem yang memudahkan Subyek serta juga memanjakan Obyek (wisatwan) kemudian wisatawan bisa dengan mudah mengetahui lokasi wisata, jalur menuju wisata dan juga bisa memebrikan review mengenaio lokasi wisata yang pernah dikunjunginya.

Sistem didefinisikan sebagai sekumpulan prosedur yang saling berkaitan dan saling berhubungan untuk melakukan suatu tugas bersamasama. Secara garis besar, sebuah sistem informasi terdiri atas tiga komponen utama. Ketiga komponen tersebut mencakup software, hardware, dan brainware. Ketiga komponen ini saling berkaitan satu sama lain [6].

Informasi adalah kumpulan data yang diolah menjadi bentuk yang lebih berguna dan lebih berarti bermanfat bagi yang menerima [7]. Berdasarkan pengertian tersebut dapat ditarik kesimpulan bahwa "Sistem informasi adalah sebuah sistem yang terdiri dari pengumpulan data, pemasukan, pemrosesan, penyimpanan, pengolahan, pengendalian dan pelaporan sehingga tercipta suatu informasi yang mendukung pengambilan keputusan didalam organisasi untuk dapat mencapai suatu tujuan tertentu bersama-sama".

Menurut UU No 10 Tentang Kepariwisataan tahun 2009 pasal 1 ayat 1 , wisata adalah kegiatan perjalanan yang dilakukan oleh seseorang atau sekelompok orang dengan mengunjungi tempat tertentu untuk tujuan rekreasi, pengembangan pribadi, atau mempelajari keunikan daya tarik wisata yang dikunjungi dalam jangka waktu sementara. Menurut UU No 10 Tentang Kepariwisataan tahun 2009 pasal 1 ayat 3, pariwisata adalah berbagai macam kegiatan wisata dan didukung berbagai fasilitas serta layanan yang disediakan masyarakat, pengusaha, pemerintah, dan pemerintah daerah. Menurut [8], Pariwisata adalah perjalanan dari suatu tempat ketempat lain, bersifat sementara dilakukan oleh perorangan atau kelompok, sebagai usaha untuk mencari keseimbangan atau keserasian dan kebahagian dengan lingkungan dalam dimensi sosial budaya alam dan ilmu.

MySQL merupakan database management system (DBMS) yang digunakan untuk merancang, mengelola, dan menyimpan database sebuah sistem atau aplikasi [9]. MySQL bersifat open source 
dibawah lisensi GPL. MySQL memiliki beberapa keuntungan, yaitu dapat berjalan di berbagai sistem operasi, dapat digunakan oleh beberapa pengguna dalam waktu bersamaan, cepat menangani query sederhana, memiliki berbagai tipe data yang banyak, dan memiliki interface terhadap beberapa aplikasi dan bahasa pemrograman dengan menggunakan fungsi $A P I$.

GPS adalah sebuah sistem telekomunikasi terbuka, tidak ada pemilikan (non-proprietary) melainkan kepemilikan hak cipta suatu perusahaan yang berkembang secara pesat dan konstan. Bagian utama dari sistem GPS adalah 24 satelit yang mengorbit Bumi di ketinggian 20.200 kilometer. Orbit satelit dirancang sehingga setiap titik di bumi dapat melihat paling sedikit empat satelit pada setiap saat akurasi atau ketepatan perlu mendapat perhatian bagi penentuan koordinat sebuah titik/lokasi [10].

\section{METODE}

Metode yang digunakan untuk teknik pengembangan sistem adalah menggunakan metode waterfall dan desain terstruktur dengan teknik penggabungan dua pendekatan yaitu pendekatan terstruktur dan pendekatan klasikal berupa life cycle.

Adapun spesifikasi dari alat dan bahan yang digunakan untuk membangun sistem dalam penelitian ini yaitu laptop dengan spesifikasi Model Processor. AMD A6-5200 kecepatan prosesor $2 \mathrm{GHz}$ Radeon HD 8400, RAM sebesar 2 GB. Software yang digunakan dalam merancang sistem adalah bahasa pemrograman PHP, singkatan dari Hypertext preprocessor yaitu bahasa pemrograman yang digunakan secara luas untuk penanganan pembuatan dan pengembangan sebuah situs web, Windows 7 Ultimate 32 bit, Tools pemodelan menggunakan microsoft Visio 2007 dan Dreamweaver dan sublime text 3 .

Use Case Diagram Sistem Informasi Wisata Berbasis Website di Kantor Dinas Pariwisata Kabupaten Kolaka Timur dapat di gambarkan seperti gambar 1 .

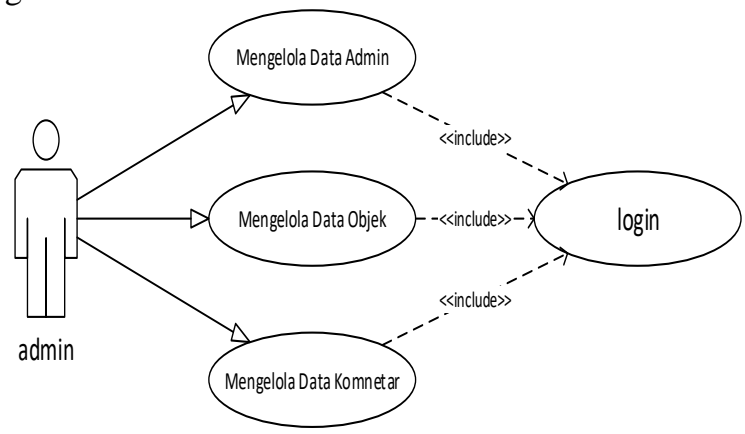

Gambar 1. Use Case Diagram Sistem Informasi Wisata Berbasis Website

Dalam perancangan sistem akan memberikan gambaran tentang sistem yang akan dibangun agar dapat lebih mudah dalam memahami alur informasi dan proses yang ada dalam sistem seperti pada gambar 2. Berdasarkan gambar 2 bahwa Admin harus melakukan input data wisata terlebih dahulu kedalam sistem, agar masyarakat dapat mengakses informasi dengan cepat dan akurat.

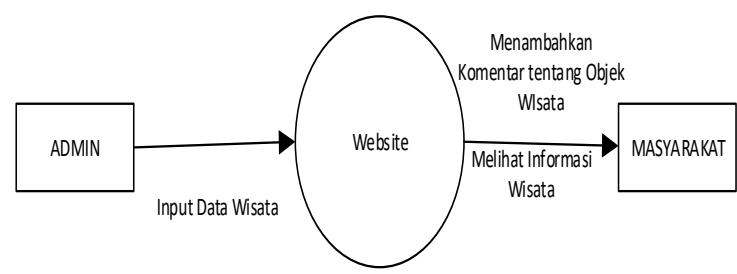

Gambar 2. Gambaran Umum Sistem

Flowchart atau diagram alir menunjukan aliran (flow) di dalam suatu program secara logika. Pada penelitian ini menggunakan Flowchart yang menjelaskan gambaran alur sistem, diawali dengan login kemudian masuk ke menu utama untuk melakukan pengelolaan user admin, data wisata seperti nama, kategori, rincian wisata, gambar, video dan komentar pada objek wisata yang dapat dilihat pada gambar 3 .

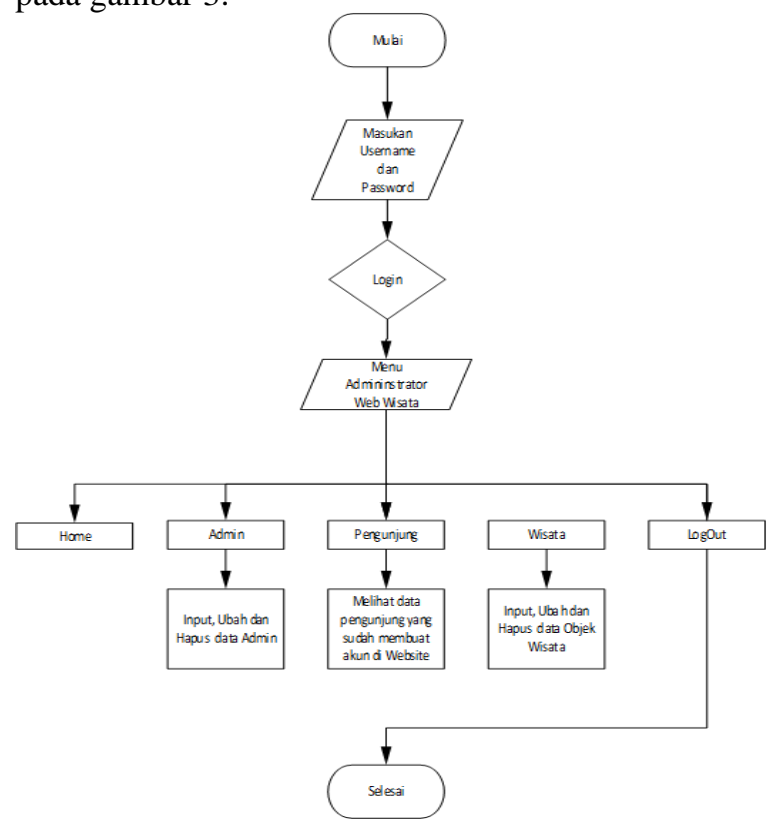

Gambar 3. Flowchart Sistem Informasi Wisata

Rancangan Struktur tabel dalam basisdata dalam sistem informasi wisata yang akan dibangun dapat dilihat pada tabel 2 .

\begin{tabular}{lll}
\multicolumn{3}{c}{ Tabel 2. Tabel Admin } \\
\hline \multicolumn{1}{c}{ Nama } & \multicolumn{1}{c}{ Tipe Data } & Keterangan \\
\hline Id_admin & Int(11) & Primary Key \\
\hline Nama & Varchar(50) & \\
\hline alamat & Text & \\
\hline email & Varchar (100) & \\
\hline No_hp & Varchar(20) & \\
\hline username & Varchar(100) & \\
\hline password & Varchar(100) & \\
\hline
\end{tabular}




Is_active $\operatorname{Int}(11)$

\section{HASIL DAN PEMBAHASAN}

Tahapan implementasi merupakan tahapan dimana sistem yang telah dirancang dan dibangun lalu diuji kelayakannya untuk selanjutnya dioperasikan sebagaimana mestinya sesuai dengan fungsi dan kelayakannya untuk digunakan oleh pihak yang membutuhkan agar mewujudkan sistem yang telah dirancang.

Gambar 4 menjelaskan tentang tampilan halaman login untuk masuk ke dalam aplikasi.

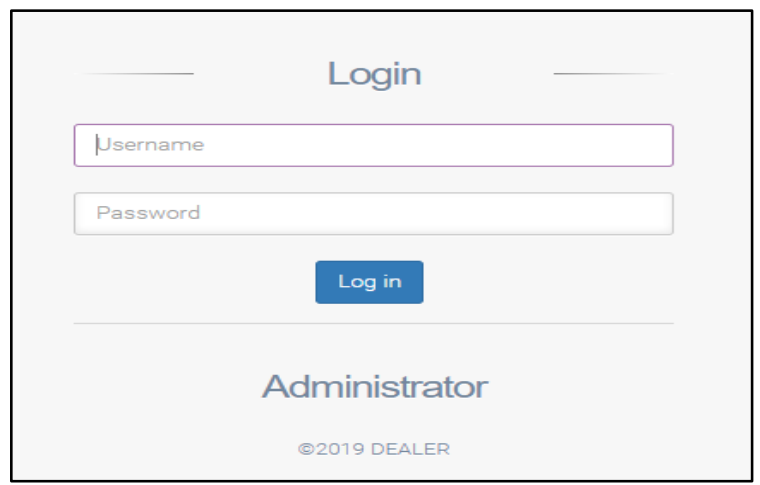

Gambar 4. Halaman Login

Kode program untuk tombol login dalam halaman Login dapat dilihat pada gambar 5.

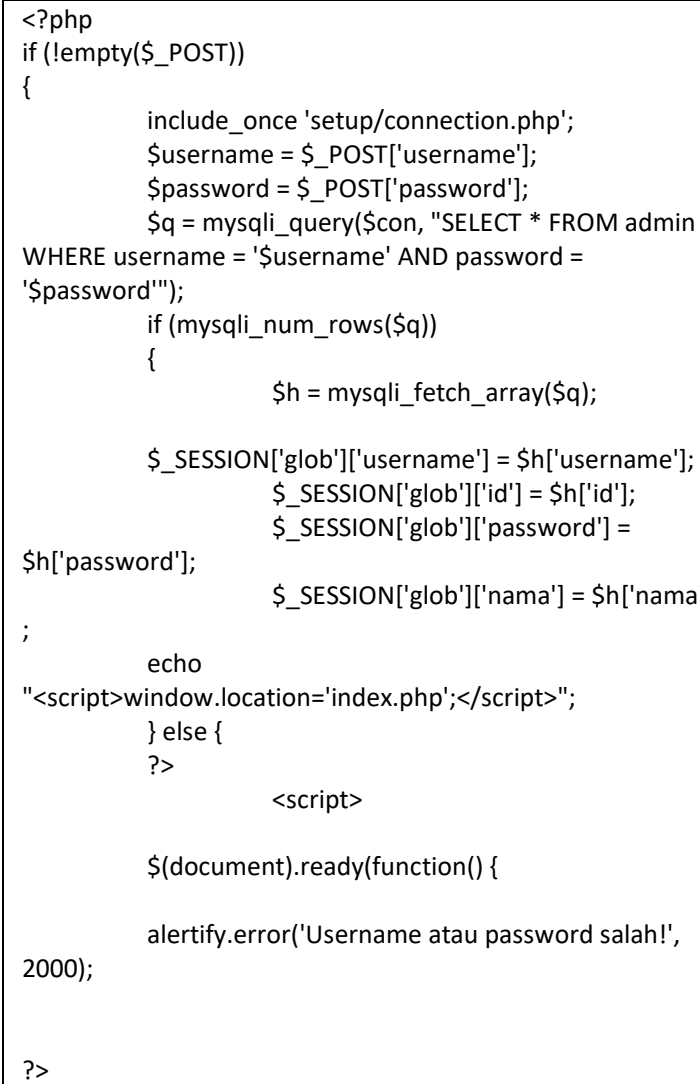

Gambar 5. Kode Program Untuk Tombol Login

Halaman utama admin merupakan halaman yang menginformasikan bahwa admin telah berhasil masuk dalam sistem administrator dan bisa melakukan pengolahan data. Tampilan halaman utama dapat dilihat pada Gambar 6.

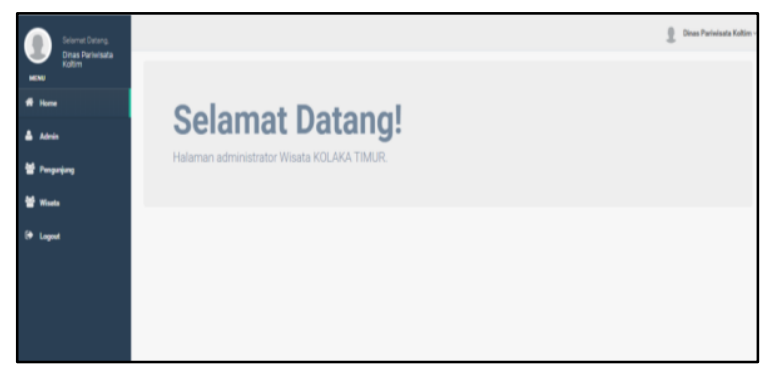

Gambar 6. Halaman Utama Admin

Kode program untuk halaman utama admin dapat dilihat pada gambar 7 . 


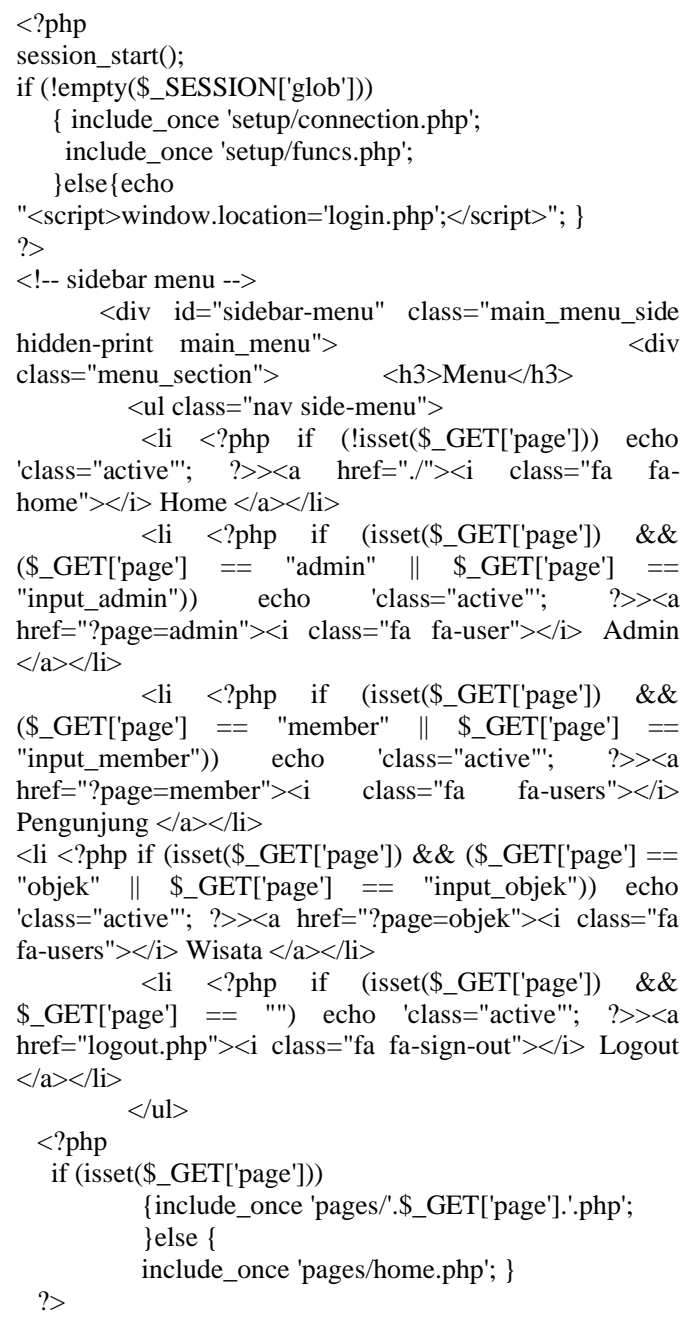

\section{Gambar 7. Kode Program Halaman Utama}

Halaman data pengunjung merupakan halaman yang menampilkan data akun pengunjung yang telah melakukan registrasi di website sistem informasi wisata. Dalam halaman ini admin hanya dapat menghapus data dari pengunjung seperti pada gambar 8 .

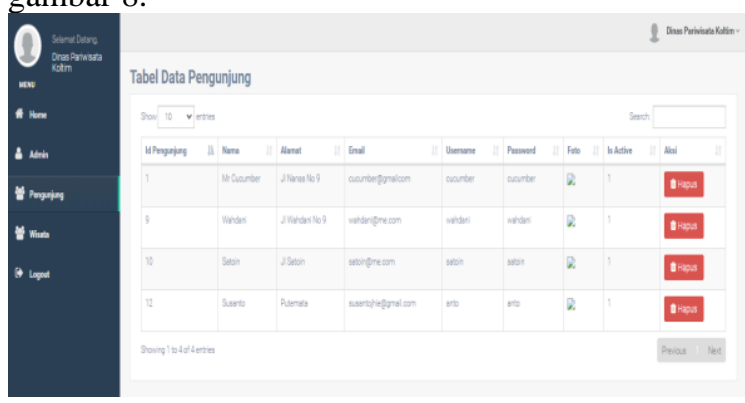

Gambar 8. Halaman Data Pengunjung

Halaman utama merupakan halaman awal yang dilihat oleh pengguna website yang berisi informasi tentang umum tentang wisata di Kolaka Timur seperti pada gambar 9.

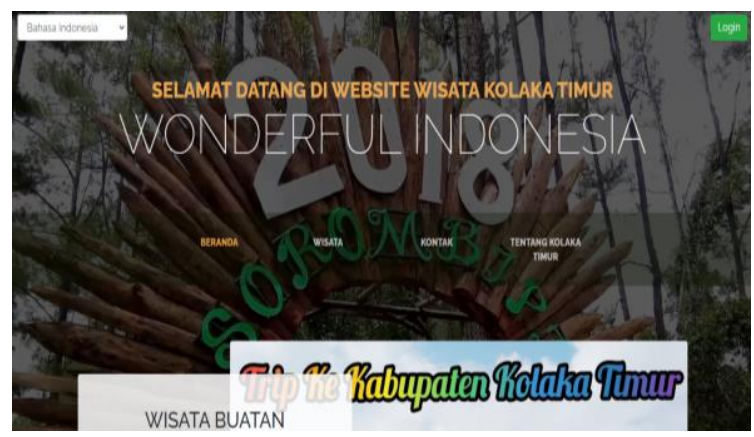

Gambar 9. Halaman utama

Halaman wisata merupakan halaman yang dilihat oleh pengguna website Ketika memilih halaman wisata (halaman wisata alam) yang berisi beberapa jumlah destinasi wisata alam di Kolaka Timur dengan sedikit informasi singkat objek wisata tersebut yang dapat dilihat pada Gambar 10.

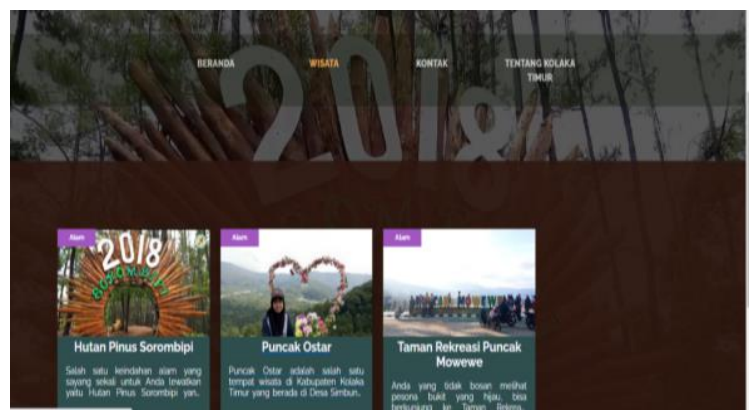

Gambar 10. Halaman Wisata (Sub Halaman Wisata Alam)

Halaman detail wisata merupakan halaman yang berisi informasi rinci tentang destinasi wisata yang di inginkan. Dalam halaman ini berisi informasi deskripsi wisata, koleksi gambar dan video, lokasi destinasi wisata, rating tempat wisata,dan juga komentar terkait tempat wisata tersebut yang dapat dilihat pada gambar 11 .

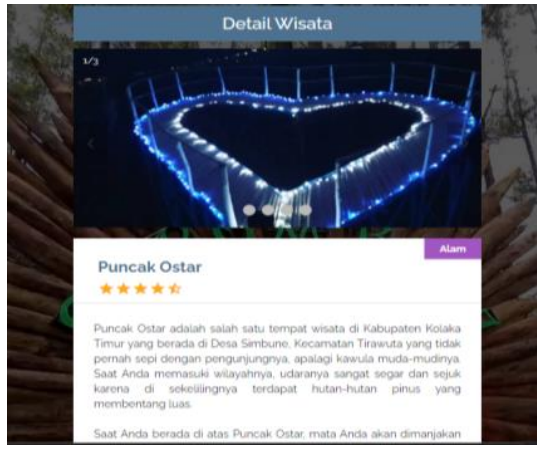

Gambar 11. Halaman Halaman Detail Wisata

Pengujian sistem dilakukan untuk memeriksa kinerja antar komponen sistem yang diimplementasikan. Tujuan utama dari pengujian sistem adalah untuk memastikan bahwa elemenelemen atau komponen-komponen dari sistem telah 
berfungsi sesuai dengan yang diharapkan. Metode pengujian yang digunakan adalah metode pengujian Black Box yang dapat dilihat pata tabel 3.

Tabel 3. Pengujian Sistem

\begin{tabular}{|c|c|c|c|c|c|}
\hline No & $\begin{array}{c}\text { Nama } \\
\text { Halaman }\end{array}$ & Langkah Pengujian & Test Case & Yang Diharapkan & Hasil \\
\hline \multirow[t]{2}{*}{1} & $\begin{array}{l}\text { Halaman } \\
\text { Login }\end{array}$ & $\begin{array}{l}\text { Mengisi form Username dan } \\
\text { Password dan menekan } \\
\text { tombol Login }\end{array}$ & $\begin{array}{l}\text { Username dan } \\
\text { Password Sesuai. }\end{array}$ & $\begin{array}{l}\text { Sistem menerima dan } \\
\text { masuk ke Halaman } \\
\text { Utama }\end{array}$ & Sukses \\
\hline & & $\begin{array}{l}\text { Mengisi form Username dan } \\
\text { Password menekan tombol } \\
\text { Login }\end{array}$ & $\begin{array}{l}\text { Username dan } \\
\text { Password Sesuai. }\end{array}$ & $\begin{array}{l}\text { Sistem tidak akan } \\
\text { menerima dan kembali } \\
\text { ke halaman login. }\end{array}$ & Sukses \\
\hline \multirow[t]{3}{*}{2} & $\begin{array}{l}\text { Menu } \\
\text { Admin }\end{array}$ & $\begin{array}{l}\text { Mengkilik tolmbol tambah } \\
\text { Admin }\end{array}$ & $\begin{array}{l}\text { Menambah } \\
\text { Admin }\end{array}$ & $\begin{array}{l}\text { Sistem menerima dan } \\
\text { akan dikirim ke } \\
\text { halaman tambah } \\
\text { admin. }\end{array}$ & Sukses \\
\hline & & $\begin{array}{l}\text { Memilih salah satu data } \\
\text { yang telah tersimpan dalam } \\
\text { tabel/grid kemudian } \\
\text { menekan tombol "Hapus" }\end{array}$ & Grid & $\begin{array}{l}\text { Sistem akan menerima } \\
\text { dan muncul pesan } \\
\text { "Yakin akan dihapus?" }\end{array}$ & Sukses \\
\hline & & $\begin{array}{l}\text { Memilih salah satu data } \\
\text { yang telah tersimpan dalam } \\
\text { tabel/grid kemudian } \\
\text { menekan tombol "Ubah" }\end{array}$ & - & $\begin{array}{l}\text { Sistem menerima dan } \\
\text { akan dikirim ke } \\
\text { halaman update. }\end{array}$ & Sukses \\
\hline \multirow[t]{3}{*}{3} & $\begin{array}{l}\text { Menu } \\
\text { Wisata }\end{array}$ & $\begin{array}{l}\text { Mengkilik tolmbol tambah } \\
\text { data }\end{array}$ & $\begin{array}{l}\text { Menambah data } \\
\text { wisata }\end{array}$ & $\begin{array}{l}\text { Sistem menerima dan } \\
\text { akan dikirim ke } \\
\text { halaman tambah wisata }\end{array}$ & Sukses \\
\hline & & $\begin{array}{l}\text { Memilih salah satu data } \\
\text { yang telah tersimpan dalam } \\
\text { tabel/grid kemudian } \\
\text { menekan tombol "Hapus" }\end{array}$ & Grid & $\begin{array}{l}\text { Sistem akan menerima } \\
\text { dan muncul pesan } \\
\text { "Yakin akan dihapus?" }\end{array}$ & Sukses \\
\hline & & $\begin{array}{l}\text { Memilih salah satu data } \\
\text { yang telah tersimpan dalam } \\
\text { tabel/grid kemudian } \\
\text { menekan tombol "Ubah" }\end{array}$ & - & $\begin{array}{l}\text { Sistem menerima dan } \\
\text { akan dikirim ke } \\
\text { halaman update. }\end{array}$ & Sukses \\
\hline 4 & $\begin{array}{l}\text { Menu } \\
\text { Pengunjung }\end{array}$ & $\begin{array}{l}\text { Memilih salah satu data } \\
\text { yang telah tersimpan dalam } \\
\text { tabel/grid kemudian } \\
\text { menekan tombol "Hapus" }\end{array}$ & Grid & $\begin{array}{l}\text { Sistem akan menerima } \\
\text { dan muncul pesan } \\
\text { "Yakin akan dihapus?" }\end{array}$ & Sukses \\
\hline 5 & $\begin{array}{l}\text { Menu } \\
\text { Komentar }\end{array}$ & $\begin{array}{l}\text { Memilih salah satu data } \\
\text { yang telah tersimpan dalam } \\
\text { tabel/grid kemudian } \\
\text { menekan tombol "Hapus" }\end{array}$ & Grid & $\begin{array}{l}\text { Sistem akan menerima } \\
\text { dan muncul pesan } \\
\text { "Yakin akan dihapus?" }\end{array}$ & Sukses \\
\hline
\end{tabular}




\begin{tabular}{|c|c|c|c|c|c|}
\hline 6 & $\begin{array}{l}\text { Menu Log } \\
\text { Out }\end{array}$ & Mengklik Menu Log Out & - & $\begin{array}{l}\text { Sistem akan menerima } \\
\text { dan kembali ke } \\
\text { halaman login. }\end{array}$ & Sukses \\
\hline 7 & $\begin{array}{l}\text { Halamn } \\
\text { Utama }\end{array}$ & Menampilkan data wisata & $\begin{array}{c}\text { Memilih salah } \\
\text { destinasi wisata } \\
\text { yang ada }\end{array}$ & $\begin{array}{l}\text { Sistem akan menerima } \\
\text { dan akan diarahkan ke } \\
\text { halaman ke detail } \\
\text { wisata }\end{array}$ & Sukses \\
\hline 8 & $\begin{array}{l}\text { Halaman } \\
\text { Wisata }\end{array}$ & $\begin{array}{l}\text { Mengisi form untuk } \\
\text { komentar }\end{array}$ & $\begin{array}{l}\text { Mengisi form } \\
\text { yang ada }\end{array}$ & $\begin{array}{l}\text { Sistem akan menerima } \\
\text { dan akan menampilkan } \\
\text { komentar terbaru di } \\
\text { halaman tersebut }\end{array}$ & Sukses \\
\hline 9 & $\begin{array}{l}\text { Halaman } \\
\text { Wisata }\end{array}$ & Mengisi form rating & $\begin{array}{l}\text { Mengisi form } \\
\text { yang ada }\end{array}$ & $\begin{array}{l}\text { Sistem akan menerima } \\
\text { dan menyimpan rating } \\
\text { baru wisata tersebut }\end{array}$ & Sukses \\
\hline 10 & $\begin{array}{l}\text { Halamn } \\
\text { Utama }\end{array}$ & Mengganti Bahasa & $\begin{array}{c}\text { Memilih Bahasa } \\
\text { yang akan } \\
\text { digunakan }\end{array}$ & $\begin{array}{l}\text { Sistem akan menerima } \\
\text { dan menggunakan } \\
\text { bahasa yang terpilih } \\
\text { untuk website }\end{array}$ & Sukses \\
\hline
\end{tabular}

\section{KESIMPULAN DAN SARAN}

Berdasarkan hasil penelitian dan pembahasan yang telah diuraikan, maka dapat ditarik kesimpulan bahwa dengan adanya sistem informasi wisata berbasis website pada Dinas Pariwiasata Kabupaten Kolaka Timur membuat masyarakat menjadi lebih mudah dalam mendapatkan informasi tentang destinasi wisata yang akurat dan efisien serta membantu dan memudahkan Dinas Pariwisata Kabupaten Kolaka Timur dalam mengelola dan memberikan pelayanan informasi wisata kepada masyarakat dengan kemudahan akses informasi.

Berdasarkan kesimpulan di atas, saran yang diajukan dalam penelitian ini adalah penerapan sistem yang baru menuntut pengguna (admin) memilki pengetahuan dalam pengoprasian sistem serta aktif dalam penggunaannya, untuk penelitian selanjutnya agar rekan-rekan atau pembaca mengembangkan sistem yang sudah ada dengan penerapan sistem informasi berbasis Android atau sebagainya agar informasi lebih mudah dan akurat lagi, Penambahan fitur rekomendasi, sehingga memudahkan wisatawan dalam memilih wisata yang akan dikunjungi.

\section{DAFTAR PUSTAKA}

BPS, Provinsi Sulawesi Tenggara Dalam Angka 2017, 2018 dan 2019. BPS, 2019.

[2] M. Suyanto, Multimedia Alat untuk Meningkatkan Keunggulan Bersaing. Sulawesi Tenggara: Andi, 2015.

[3] Arsad, "Perancangan Sistem Informasi Pariwisata
Berbasis Web Di Dinas Kebudayaan dan Pariwisata Kabupaten Muna," Universitas Islam Negeri Syarif Hidayatullah Jakarta, 2011.

[4] R. P. N. S. H. Ningsih, "Sistem informasi pariwisata daerah Kabupaten Wonogiri berbasis web," 2011.

[5] A. N. Sari, "Pengembangan Sistem Informasi Pariwisata Surakarta dengan Menggunakan Macromedia Flash," Pengembangan Sistem Informasi Pariwisata Surakarta dengan Menggunakan Macromedia Flash, 2007.

[6] I. P. A. E. Pratama, Sistem Informasi dan Implementasinya. Bandung: Informatika Bandung, 2014.

[7] E. Nugroho, Sistem Informasi Manajemen. Yogyakarta: Andi Yogyakarta, 2010.

[8] I. J. Dewi, Implementasi dan Implikasi Kelembagaan Pemasaran Pariwisata yang Bertanggung Jawab(Responsible Tourism Marketing). KEMENTERIAN KEBUDAYAAN DAN PARIWISATA REPUBLIK INDONESIA, 2011.

[9] O. Corporation, "MySQL," 2015. www.mysql.com (accessed Nov. 26, 2021).

[10] S. Alfeno and R. E. C. Devi, "Implementasi Global Positioning System (GPS) dan Location Based Service (LSB) pada Sistem Informasi Kereta Api untuk Wilayah Jabodetabek," Sisfotek Glob., vol. 7, no. 2, pp. 27-33, 2017, [Online]. Available: https://journal.stmikglobal.ac.id/index.php/sisfote k/article/view/146. 